\title{
Synthesis of Silver Nanoparticles using Egg White: Dye Degradation and Antimicrobial Potential
}

\author{
Ankush Kaushik $^{1(\mathbb{D})}$, Deepak Gola ${ }^{1}(\mathbb{D})$, Jyoti Raghav ${ }^{1(\mathbb{D}}$, Dhriti Gupta ${ }^{1(\mathbb{D}}$, Arvind Kumar ${ }^{1}{ }^{(\mathbb{D}}$, Meenu

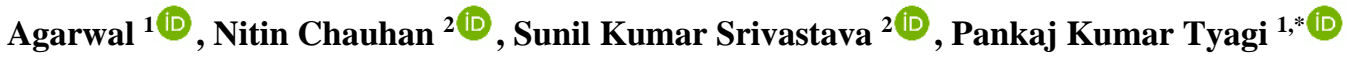 \\ 1 Noida Institute of Engineering and Technology, Greater Noida, Uttar Pradesh, India \\ 2 Department of Microbiology, Swami Shraddhanand College, University of Delhi, Delhi, India \\ * Correspondence: pktgenetics@ gmail.com (P.K.T.);
}

Scopus Author ID 34881106500

Received: 9.05.2021; Revised: 7.06.2021; Accepted: 10.06.2021; Published: 18.06.2021

\begin{abstract}
In recent years, developing nanoparticles with green processes is gaining huge attention due to its cost-effectiveness, simplicity and non-toxic precursors. The present study utilized the potential of egg white for the synthesis of stable silver nanoparticles (EW-AgNPs). In order to characterize the EWAgNPs, various techniques have been employed. $U V$-vis spectroscopy (300-700nm) was used to study the $\lambda_{\max }$, which highlighted the peak at $422 \mathrm{~nm}$. Further, the stability of synthesized EW-AgNPs was studied using Zeta potential, the value of $-16.4 \mathrm{mV}$ was obtained, indicating the stability of developed EW-AgNPs in the solution. Transmission electron microscopy was used specifically to visualize the shape and size of synthesized EW-AgNPs, the images showed spherical to the diverse shape of EWAgNPs. In the first phase, the EW-AgNPs were studied for dye degradation along with $\mathrm{NaBH}_{4}$. The enhanced dye degradation of blue dye was obtained with EW-AgNPs $+\mathrm{NaBH}_{4}$, showing 90- 100\% degradation from 100- $25 \mathrm{mgL}^{-1}$ dye solution, respectively. Further, in the second phase, antimicrobial activity (Zone of Inhibition) of EW-AgNPs was analyzed against Escherichia coli and Staphylococcus aureus. A higher ZOI was obtained for E.coli $(16 \mathrm{~mm})$ than $S$. aureus $(12.4 \mathrm{~mm})$. The present study proved egg white's ability to develop stable silver nanoparticles, which was further found to be effective for blue dye degradation and antimicrobial activity.
\end{abstract}

Keywords: egg white; silver nanoparticles; TEM; dye degradation; antimicrobial agent.

(C) 2021 by the authors. This article is an open-access article distributed under the terms and conditions of the Creative Commons Attribution (CC BY) license (https://creativecommons.org/licenses/by/4.0/).

\section{Introduction}

Textiles dyes are classified into two major groups, i.e., organic dyes and synthetic dyes [1-3]. Organic dyes are obtained from natural sources, like a flower, leaves, roots, etc. On the other hand, synthetic dyes are developed through chemical processes. The organic dyes are non-toxic and degradable [4], whereas synthetic dyes are toxic and may be categorized into xenobiotic compounds [5,6]. The paper and textile industries are the major industries that utilize synthetic dyes for coloring paper and clothes. A major part of the dyes remained unutilized during the colorization process and discarded as effluent [6]. The colored effluent is discharged into the nearby water bodies and is the source of toxicity to the living aquatic organisms [7]. In addition to this, the color of dye reduces light penetration, which directly affects the life forms on aquatic sources [8]. Further, irrigation with such wastewater transfers dye and its components into the plants [9, 10]. Many physical, chemical, biological methods or combinations of these have been developed to remove or degrade the dye from synthetic as well as actual wastewater. The physio-chemical methods are fast but require more energy and 
can produce toxic metabolites during the degradation process [5]. On the other hand, biological methods employ micro-organism (such as bacteria, fungi, or algae) to degrade the dye complex into a simpler component with low energy requirements [11].

The degradation of dye through metallic nanoparticles is gaining attention due to the high efficacy against different types of synthetic dyes such as reactive, azo, anionic, etc [7]. The synthesis of metallic nanoparticles by various processes and their utilization is one of the evolving research areas of nanotechnology [12-14]. Various methods have been employed to synthesize nanoparticles that can be categories into physical, chemical, and biological processes. The physical and chemical methods require high energy and toxic chemicals or reagents during the synthesis of nanoparticles. On the other hand, the biological methods utilize plants, bacteria, fungi, algae, etc., for the synthesis of nanoparticles [15-19]. However, the generation of egg-based nanoparticles is very limited [20-22]. The albumin protein present in the white chicken egg has a large potential for the generation of nanoparticles. Gold, silver, cadmium, copper, iron, etc., are some metals that have been widely exploited as a source of nanoparticles using biological methods [12]. However, the synthesis of silver nanoparticles has been researched primarily due to their application in the health care sector, biosensors, food industry, wastewater treatment, etc. [12, 23-26]. Available literature indicates the degradation of toxic textile dyes using metallic nanoparticles generated by plants, fungus, bacteria, etc. [27$31]$.

The degradation of dye using nanoparticles generated by egg white was not available in the existing literature studies. Therefore, the present study utilized the gap mentioned above and studied the degradation kinetic of a dye using egg white-based nanoparticles. For the same, chicken egg was used for the biosynthesis of silver nanoparticles under sunlight. The silver nanoparticles were examined for their morphological characteristics such as shape, surface charge and size through UV-spectroscopy, TEM, and Zeta-DLS. Further, the nanoparticles were examined for their potential to decolorize the synthetic dye along with decolorization kinetic. In addition to this, the synthesized nanoparticles were investigated for their antimicrobial potential against gram-positive and gram-negative bacteria.

\section{Materials and Methods}

\subsection{Chemical and dye.}

All the chemicals and reagents used in the present experiment were of analytical grade. For the dye decolorization experiment, blue dye was procured from the leading textile industry (Madhya Pradesh, India). The $100 \mathrm{~mL}$ of stock solution $\left(1000 \mathrm{mg} \mathrm{L}^{-1}\right)$ for silver nitrate $\left(\mathrm{AgNO}_{3}\right.$, Qualigen) and blue dye was prepared in the double-distilled water. Sodium borohydride $\left(\mathrm{NaBH}_{4}\right)$ salt for experiments was obtained from $\mathrm{CDH}$ (Chandigarh, India) and 10 $\mathrm{mL}$ solution $(0.1 \mathrm{M})$ of sodium borohydride was prepared for future experiments. Prior to experimentation, all the glassware was cleaned in an acidic solution.

\subsection{Synthesis of egg white silver nanoparticles (EW-AgNPs).}

The previously defined protocol was modified for the synthesis of silver nanoparticles using egg white [32]. The chicken eggs were collected from the Institute canteen and egg white from the egg was collected in a beaker. Around $2 \mathrm{~mL}$ of egg white was mixed with $92 \mathrm{~mL}$ of double distilled water and the mixture was stirred at $120 \mathrm{rpm}$ for $50 \mathrm{~min}$. Further, the solution was filtered through Whatman no 1 paper. Afterward, the filtrate is mixed with $6 \mathrm{~mL}$ of $\mathrm{AgNO}_{3}$ 
solution (1000 $\left.\mathrm{mg} \mathrm{L}^{-1}\right)$ in a drop-wise manner with continuous stirring at $120 \mathrm{rpm}$ ) to obtain $100 \mathrm{~mL}$ reaction solution. After adjusting the $\mathrm{pH}$ of the reaction solution at a value 7.2 , the solution was kept under sunlight for $50 \mathrm{~min}$ for the synthesis of silver nanoparticles. To observe the synthesis of silver nanoparticles, a sample was scanned between $300 \mathrm{~nm}$ to $700 \mathrm{~nm}$ at a regular interval.

\subsection{Dye degradation activity of EW-AgNPs.}

The blue dye decolorization activity using EW-AgNPs was observed at different concentrations of dye ranging from $25 \mathrm{~m} \mathrm{~L}^{-1}$ to $100 \mathrm{mg} \mathrm{L}^{-1}$. For the same, $2.0 \mathrm{~mL}$ of blue dye solution of desired concentration was mixed with $0.05 \mathrm{~mL}$ of EW-AgNPs solution along with $0.05 \mathrm{~mL}$ of $\mathrm{NaBH}_{4}$ solution $(0.1 \mathrm{M})$ in quartz cuvette of $4.0 \mathrm{~mL}$. Further, to observe the decolorization ability of $\mathrm{NaBH}_{4}$ solution $(0.1 \mathrm{M})$ alone, $2 \mathrm{~mL}$ of dye sample of desired concentration was mixed with $0.05 \mathrm{~mL}$ of $\mathrm{NaBH}_{4}$ solution. A solution in the cuvettes was mixed constantly using a $0.1-1.0 \mathrm{~mL}$ pipette. The solution in the cuvette was observed for $\lambda_{\max }$ (blue dye) at regular intervals to obtain the decolorization kinetic of blue dye.

The decolorization of dyes in term of percentage was calculated as per the equation given below:

$$
\text { Dye degradtion } \%=\frac{A o-A t}{A o} \times 100
$$

Further, to determine the degradation kinetic of dye, the following equation was used:

$$
\text { In } \frac{A t}{A o}=-\mathrm{kt}
$$

where $\mathrm{Ao}=$ maximum absorbance at zero time; $\mathrm{At}=$ maximum absorbance at $\mathrm{t}$ time and $\mathrm{k}=$ degradation rate constant

\subsection{Antibacterial activity of EW-AgNPs.}

Antibacterial activity of EW-AgNPs was studied in terms of zone of inhibition (ZOI) against gram-negative (E. coli) and gram-positive ( $S$. aureus) bacteria through the disc diffusion technique. The antibacterial activity of EW-AgNPs was compared with the readily available antibiotic discs. For the same, freshly grown bacterial cultures of $24 \mathrm{~h}$ were spread on the nutrient agar plates. After spreading, five different discs containing double distilled water, $\mathrm{AgNO}_{3}$ solution, egg white protein solution, EW-AgNPs and antibiotics (penicillin and kanamycin) were placed on the nutrient agar plate. All the bacterial inoculated plates were incubated for $24 \mathrm{~h}$ at $37^{\circ} \mathrm{C}$.

\subsection{Analytical techniques.}

\subsubsection{UV-Visible spectrophotometer.}

The formation of EW-AgNPs due to the reduction of silver ions to silver nanoparticles in the presence of sunlight was monitored at regular. For the same, $3 \mathrm{~mL}$ solution was withdrawing from the reaction solution to quartz cuvette (path length: $10 \mathrm{~mm}$ ). The reaction solution was scanned between $300 \mathrm{~nm}$ to $700 \mathrm{~nm}$ using a UV-Visible spectrophotometer (Shimadzu). On the other hand, the blue dye diluted solution was scanned between $300 \mathrm{~nm}$ to $700 \mathrm{~nm}$ to obtained maximum absorbance $\left(\lambda_{\max }\right)$. All the dye decolorization studies were observed at the resultant maximum absorbance. 
2.5.2. Transmission electron microscopy (TEM).

To examine the size and shape of the EW-AgNPs, transmission electron microscopy was performed. The reaction solution was placed on the carbon-coated grid. Afterward, to dry the grid, it was kept at room temperature for $2 \mathrm{~h}$ and to obtain the TEM micrograph, the sample on the grid was analyzed using EOL JEM-1400.

\subsubsection{Zeta potential and Dynamic Light Scattering (DLS).}

The surface charge is one of the most important properties of silver nanoparticles that directly influence the stability of the silver nanoparticles. To examine the surface charge on the EW-AgNPs, the zeta potential was performed through Malvern-Zeta- sizer. In addition to this, the size distribution of EW-AgNPs was analyzed through DLS. DLS micrograph of EWAgNPs was recorded through Malvern-Zeta- sizer (MAL1017202).

\section{Result and Discussion}

\subsection{Ultraviolet-visible spectroscopy.}

UV-visible spectroscopy is the most widely used technique to check the synthesis of metallic nanoparticles. The change in color of the reaction mixture from transparent solution to dark brown is the primary indication of silver nanoparticle synthesis. The change in color of the reaction mixture is due to the reduction reaction in $\operatorname{Ag}^{+}$to $\mathrm{Ag}^{0}$ [7, 33]. Further, $\mathrm{UV}-\mathrm{Visible}$ spectrum was obtained for SPR bands present due to silver nanoparticles.

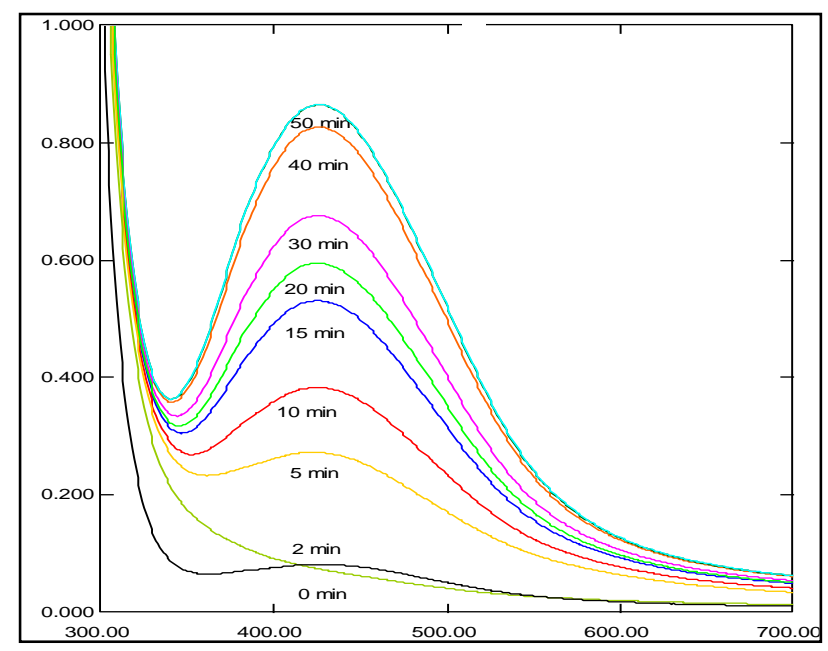

Figure 1. UV-Visible spectrum of EWAgNPs with time.

As illustrated in Figure 1, a sharp absorbance peak at $422 \mathrm{~nm}$ ( $\lambda$ max) was observed at different time intervals, indicating the formation of nanoparticles under the presence of sunlight in the range of nanometers [7,34]. Figure 1 indicates that the reduction reaction of $\mathrm{Ag}^{+}$to $\mathrm{Ag}^{0}$ during the synthesis of the silver nanoparticles is time-dependent. The absorbance peak increases with the increase in sunlight exposure as the reduction reaction for the synthesis of silver nanoparticles is still under process. After $50 \mathrm{~min}$, no change in absorbance peak was observed, indicating a complete reduction of available silver ions to silver nanoparticles. 


\subsection{Zeta Potential and DLS.}

Figure 2 illustrates the zeta potential of EW-AgNPs after the incubation period of 50 min under sunlight. The zeta potential examined the surface property of EW-AgNPs in terms of potential or charge. In the present experiment, EW-AgNPs indicate $-16.4 \mathrm{mV}$ values which clearly showed negative charges on the synthesized nanoparticles. EW-AgNPs acquire a negative charge due to the binding of proteins present in the egg white. These proteins act as a capping agent during the synthesis of nanoparticles and provide stability to the nanoparticles. The zeta potential value of EW-AgNPs demonstrated the electrostatic repulsion between the synthesized silver nanoparticles in solution and prevented its agglomeration. A high negative value indicates good colloidal nature, high dispersity and a high degree of stability of EWAgNPs. A similar negative value was observed for other nanoparticles synthesized utilizing egg white, plant, fungi, etc. [12]. The value of $-24.2 \mathrm{mV}$ indicates a negative surface charge on the silver nanoparticles synthesized using egg white protein [32]. In another case, $-25.1 \mathrm{mV}$ zeta potential was recorded for the silver nanoparticles synthesized by using flower extract of Ipomoea digitata.

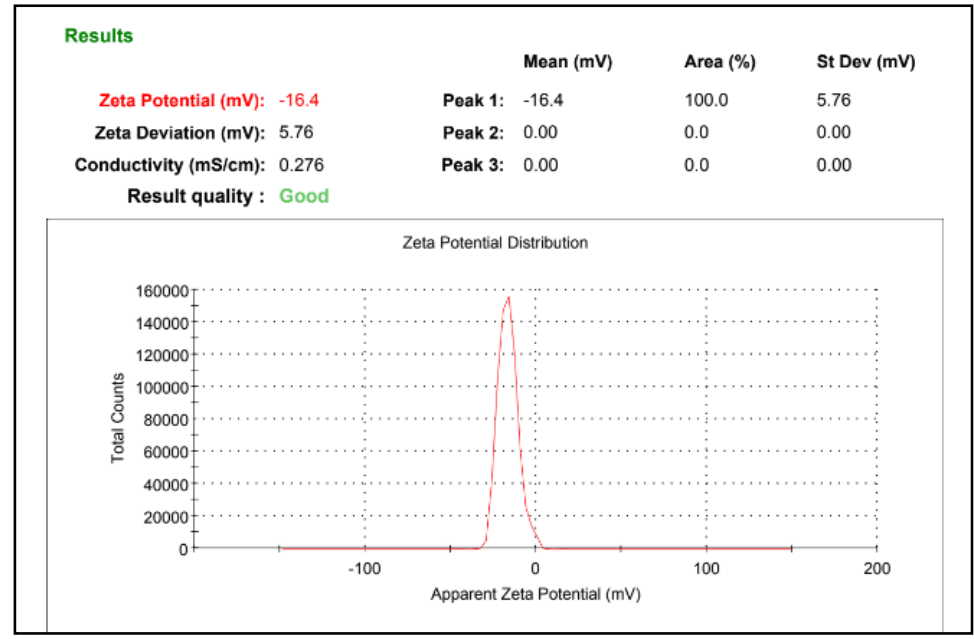

Figure 2. Zeta potential micrograph of EW-AgNPs

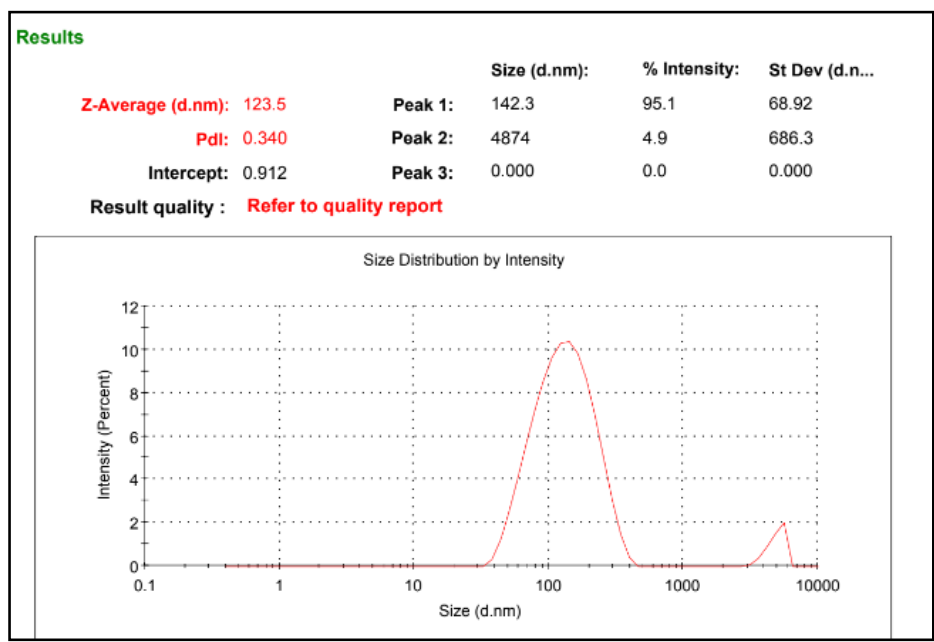

Figure 3. DLS micrograph of EWAgNPs

Further, figure 3 illustrates that PDI value of EW-AgNPs was 0. The PDI value for the metallic nanoparticles occurs between 1 to 0 . Value " 0 " in PDI index indicates a monodisperse distribution of silver nanoparticles, while the value " 1 " indicates a polydisperse distribution of silver nanoparticles [35]. In the present study, the PDI value of EW-AgNPs indicates the 
formation of monodisperse distribution of nanoparticles. In other studies, PDI value for the silver nanoparticles exists between 0.11 to $0.42[36,37]$.

\subsection{Transmission electron microscopy.}

Shape and size are the important physical properties of nanoparticles that directly control the applications of nanoparticles, i.e., Dye degradation, antifungal, antibacterial, bioremediation, etc. To identify the shape and size of nanoparticles, TEM were employed. Figure 4 illustrates the TEM micrograph of EW-AgNPs and it indicates the synthesis of spherical- diverse shaped nanoparticles. Further, the size of EW-AgNPs was observed to be roughly around $25 \mathrm{~nm}$ through TEM image.

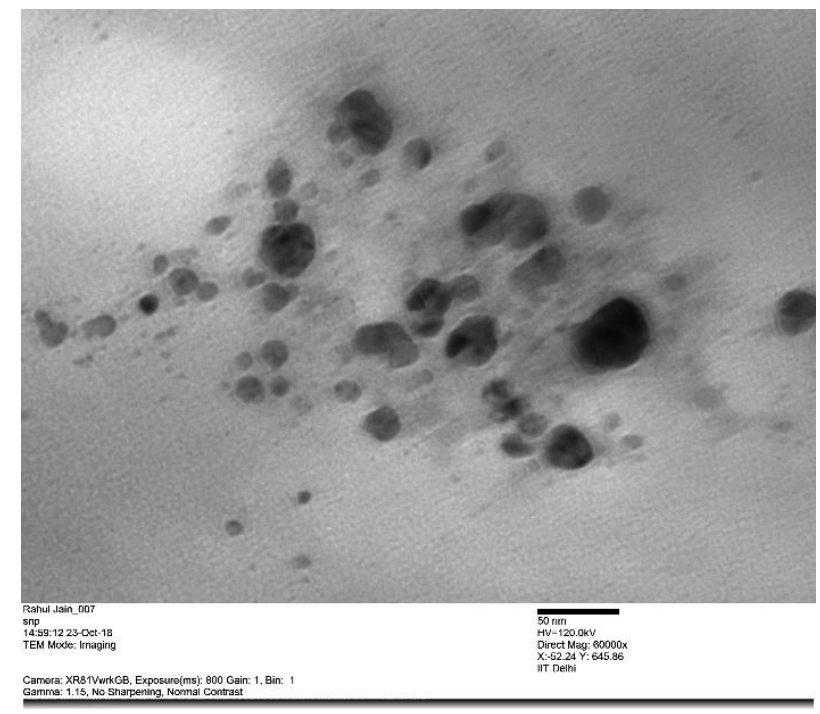

Figure 4. TEM micrograph of EWAgNPs.

Various synthesizing parameters influence the shape and size of the developing nanoparticles, i.e., the concentration of silver nitrate used, $\mathrm{pH}$ of the solution, temperature, light, incubation period, etc. [38,39]. These parameters help the nanoparticle to attain different shapes and sizes during the synthesis process. Further, the shape and size play an important role in metallic nanoparticles' antimicrobial and catalytic activity. For example, sharp-ended nanoparticles (triangular and hexagonal) can easily penetrate the cell wall and membrane during antimicrobial activity and are found more efficient than spherical and oval-shaped nanoparticles [40]. Further, degradation of pollutants such as dye, antibiotics, pesticide, etc., occurred on the surface of nanoparticles. Smaller size nanoparticles provide more surface area during catalytic activity than large-sized nanoparticles and, therefore, smaller-sized nanoparticles will show high catalytic activity [41].

\subsection{Dye degradation activity.}

Silver nanoparticles are well known for removing toxic dyes, antibiotics, pesticides etc., like pollutants from wastewater. In the present study, the EW-AgNPs were employed for the remediation of dye from synthetic wastewater. The catalytic activity of EW-AgNPs was estimated in terms of decolorization of dyes from the synthetic wastewater present at a different initial concentration ranging from $25 \mathrm{mg} \mathrm{L}^{-1}$ to $100 \mathrm{mgL}^{-1}$. A decrease in the absorbance value at $\lambda$ max for dye $(612 \mathrm{~nm})$ indicates the decolorization process caused by the EW-AgNPs on its surface. It was observed that no significant change in dye-containing synthetic wastewater 
occurred when exposed to $\mathrm{NaBH}_{4}$ (Figure 5A). On the other hand, when EW-AgNPs were used along with $\mathrm{NaBH} 4$ in the dye-containing synthetic wastewater, up to $90-100 \%$ decolorization was observed. The decolorization process of blue dye caused by the catalytic activity of EWAgNPs was measured in terms of a decrease in absorbance peak with time, as shown in figure $5 \mathrm{~B}$.
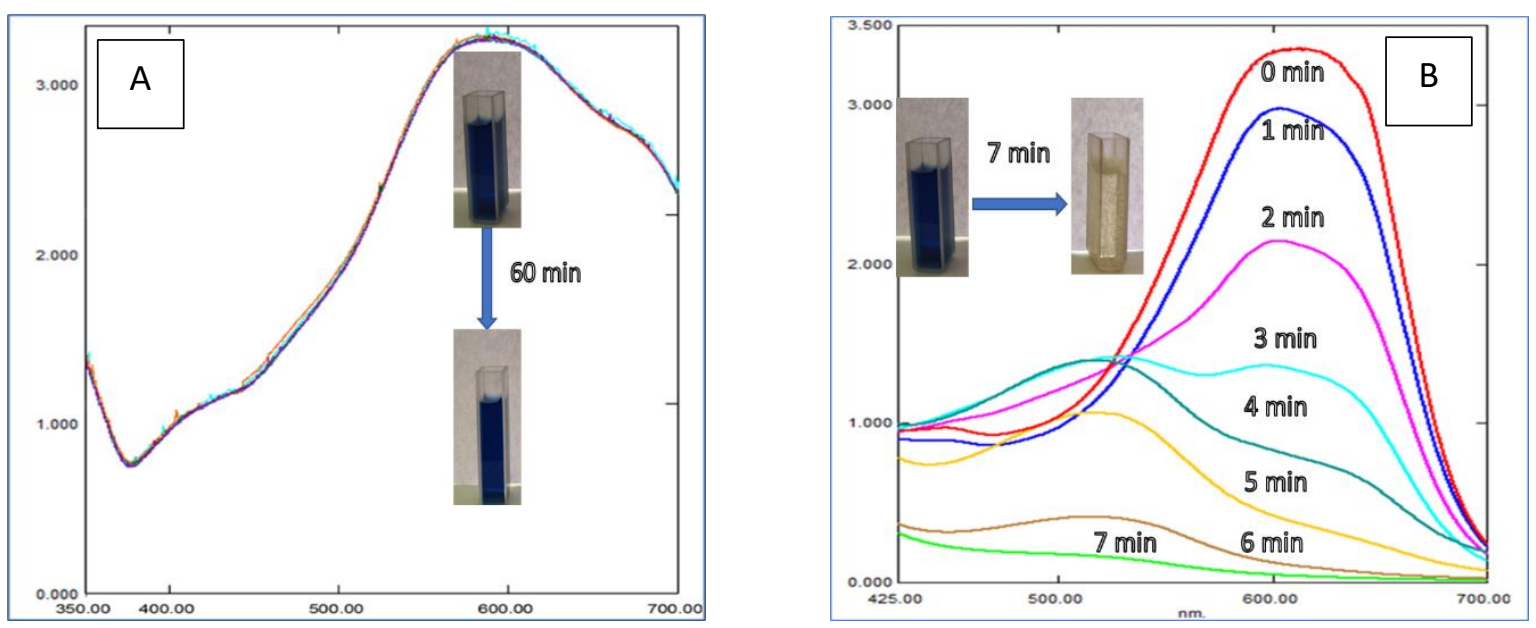

Figure 5. Blue dye degradation in presence of $\mathrm{NaBH}_{4}$ and $\mathrm{EW}-\mathrm{AgNPs}+\mathrm{NaBH}_{4}$ at $100 \mathrm{mgL}^{-1}$.

Table 1 indicates the percentage of dye colorization at different concentrations caused by EW-AgNPs. Up to $100 \%$ decolorization was observed at $25 \mathrm{mgL}^{-1}$, whereas at $100 \mathrm{mgL}^{-1}$ the decolorization reduces to $90.3 \%$. It was observed that, as the initial dye concentration increases in the synthetic wastewater, the time required for complete decolorization was also increased. The possible reason for the increased decolorization time may be the development of multi-layer of dye molecule onto the surface of EW-AgNPs that restricts the penetration of light, which is required during the degradation of dye into colorless products. Further, the surface of EW-AgNPs acts as an electron relay system during the degradation reaction of dye present in synthetic wastewater. The probable mechanism of dye degradation caused by EWAgNPS in the presence of $\mathrm{NaBH}_{4}$ includes the transportation of electrons from $\mathrm{NaBH}_{4}$ to dye molecule via EW-AgNPs.

Table 1. Dye degradation percentage at different dye concentrations ranging from $25 \mathrm{mgL}^{-1}$ to $100 \mathrm{mgL}^{-1}$.

\begin{tabular}{c|c|c} 
& \multicolumn{2}{|c}{ Dye decolorization (\%) } \\
\hline Concentration $\left(\mathrm{mgL}^{-1}\right)$ & $\mathrm{NaBH}_{4}$ & $\mathrm{NaBH}_{4}+$ EWAgNPs \\
\hline $25 \pm 0.48$ & $10.4 \pm 0.04$ & $100 \pm 3.22$ \\
\hline $50 \pm 1.56$ & $0.81 \pm 0.02$ & $100 \pm 1.34$ \\
\hline $75 \pm 3.20$ & $0.00 \pm 0.01$ & $94.2 \pm 2.45$ \\
\hline $100 \pm 2.52$ & $0.00 \pm 0.01$ & $90.3 \pm 2.80$
\end{tabular}

Firstly, both Bohorhydride ion $\left(\mathrm{BH}_{4}^{-}\right)$and dye molecule absorbed on the surface of EW-AgNPs. Further, $\mathrm{BH}_{4}^{-}$ion acts as a nucleophilic agent, which donates its available electron to EW-AgNPs. On the other hand, dye molecules absorbed on the surface of EW-AgNPs will act as an electrophilic agent and capture the electron available on the surface of EW-AgNPs. This overall process starts a relay of dye degradation reaction and breaks the dye molecule into a colorless component. The degradation kinetics of blue dye follows the first-order degradation kinetic at $100 \mathrm{mgL}^{-1}$ initial dye concentration. The first-order degradation kinetic can be depicted by the linear relationship between $\operatorname{In}[\mathrm{At} / \mathrm{Ao}]$ (At: Absorbance at time " $\mathrm{t}$ " and Ao: Absorbance at " 0 min") and $t$ (degradation time). As illustrated in figure 6, a linear relationship was observed between At/Ao and time for degradation of blue dye. The rate of degradation for 
blue dye was found to be $0.187 \mathrm{~min}^{-1}$. A similar increase in degradation rate was observed for the other dyes such as malachite green, congo red, thymol blue, methyl orange etc. [27, 4244].

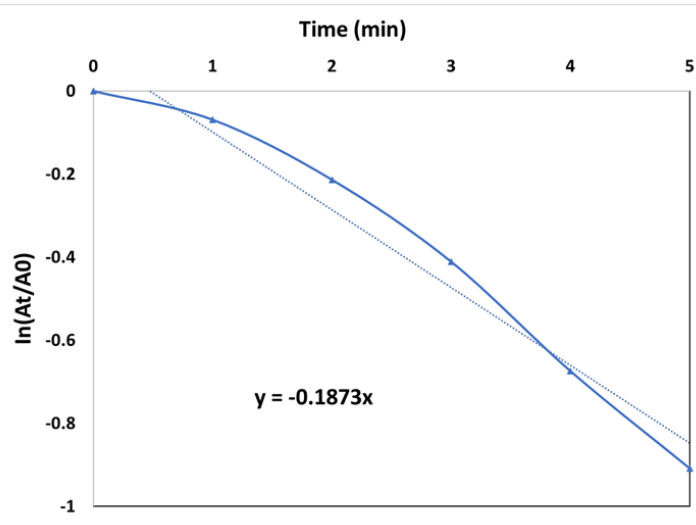

Figure 6. Blue dye degradation in presence of EWAgNPs $+\mathrm{NaBH}_{4}$ at $100 \mathrm{mgL}^{-1}$

\subsection{Antimicrobial activity of EW-AgNPs.}

Metallic nanoparticles are well known for their antimicrobial activities against multiples pathogenic bacteria as well as pathogenic fungus. The shape of the metallic nanoparticles plays an important role in their antimicrobial activity. In the present study, the antimicrobial activity of EW-AgNPs was evaluated against two bacterial species, i.e., E. coli and $S$. aureus. The antimicrobial activity of EW-AgNPs was analyzed in terms of zone of inhibition (ZOI) results, as illustrated in Table 2.

Table 1. Antibacterial activity of plant extract, $\mathrm{AgNO}_{3}$ solution, EWAgNPs and antibiotics against E. coli and S. aureus.

Zone of Inhibition (mm)

\begin{tabular}{l|l|l|l|l|l}
\hline Bacteria & EW & AgNO $_{3}$ solution & EWAgNPs & Penicillin & Kanamycin \\
\hline Escherichia coli & & $0.5 \pm 0.01$ & $16.0 \pm 0.41$ & $18.2 \pm 0.66$ & $14.0 \pm 0.36$ \\
\hline Staphylococcus aureus & & $0.2 \pm 0.02$ & $12.4 \pm 0.23$ & $16.1 \pm 0.58$ & $16.4 \pm 0.37$
\end{tabular}

The results clearly indicated that the antimicrobial activity of EW-AgNPs was on the higher side for $E$. coli $(16.0 \mathrm{~mm})$ compared to $S$. aureus $(12.4 \mathrm{~mm})$. The difference in cell wall thickness and composition (thick peptidoglycan in gram-positive S. aureus) can be the possible reason for the higher antimicrobial activity against E. coli compared to $S$. aureus. Further, it was observed that the antimicrobial activity of EW-AgNPS was comparable to commercial antibiotics. The ZOI value of penicillin and kanamycin for E. coli was $18.2 \mathrm{~mm}$ and $14.2 \mathrm{~mm}$, respectively. The performance of EW-AgNPs for E.coli was better than kanamycin. On the other hand, for $S$. aureus, the ZOI value of penicillin and kanamycin was $16.1 \mathrm{~mm}$ and 16.4 $\mathrm{mm}$, respectively. The presence of a thick peptidoglycan layer in gram-positive bacteria $(S$. aureus) restricts the entry of silver nanoparticles inside of the cell. On the other hand, the peptidoglycan layer in the gram-negative bacteria (E. coli) is very thin. It, therefore, provides easy passage for nanoparticles to enter inside the cell. Hence gram-negative bacterial species are more susceptible to nanoparticles [40,45]. Once nanoparticles enter the cell, it interacts with the DNA (deoxyribonucleic acid), degrades enzymes and proteins resulted in the cell death [12]. It was also observed that silver ions can intercalate between the DNA base pairs and cause cell damage. Silver nanoparticles can also induce the process of apoptosis by increasing the level of reactive oxygen species and intracellular calcium concentration $[40,46]$. Further, the shape of the nanoparticle also plays an important role in its antimicrobial activity. 
Spherical, triangular, circular, hexagonal, etc., are some common shapes that have been identified [12, 38]. Some studies suggested that nanoparticles with sharp ends (triangular or hexagonal) show higher antimicrobial activity as compared to spherical or circular-shaped nanoparticles. The available sharp end present in the triangular and hexagonal shaped nanoparticles can easily penetrate the bacterial cell membrane and, therefore, show significantly higher antimicrobial activity than spherical or circular shaped nanoparticles [40].

The above results indicated that the nanoparticles synthesized by egg white protein have good potential for rapid degradation of toxic textile dye along with the significant antimicrobial activity. The process can be further optimized to maximize dye degradation at a maximum rate with minimum inputs.

\section{Conclusions}

The present study successfully demonstrated the efficacy of egg white portion for stable silver nanoparticles (EW-AgNPs) synthesis. The developed EW-AgNPs were characterized using various analytical techniques, such as $U V$-vis spectroscopy, Zeta-DLS, TEM etc. The analysis showed the efficient synthesis of silver nanoparticles which were stable in colloidal solution with spherical-diverse shapes. Further, the developed EW-AgNPs were found to be effective against E.coli and S. aureus. The EW-AgNPs also highlighted the enhanced degradation potential for blue dye. It is now clear that this simple, economical and eco-friendly process can be harnessed for sustainable nanotechnology. The present study strengthens the need to study the potential of egg white further to develop various other metallic nanoparticles which can be used for different applications.

\section{Funding}

This research received no external funding.

\section{Acknowledgments}

The authors greatly acknowledge the support provided by the Noida Institute of Engineering and Technology, Swami Shraddhanand College, University of Delhi and IIT Delhi (Applied Microbiology Laboratory, CRDT) for their kind support.

\section{Conflicts of Interest}

The authors declare no conflict of interest.

\section{References}

1. Hasanpour, M.; Hatami, M. Photocatalytic Performance of Aerogels for Organic Dyes Removal from Wastewaters: Review Study. Journal of Molecular Liquids 2020, 309, 113094, https://doi.org/10.1016/j.molliq.2020.113094.

2. Tkaczyk, A.; Mitrowska, K.; Posyniak, A. Synthetic Organic Dyes as Contaminants of the Aquatic Environment and Their Implications for Ecosystems: A Review. Science of the Total Environment 2020, 717, 137222, https://doi.org/10.1016/j.scitotenv.2020.137222.

3. Golmohammadi, M.; Honarmand, M.; Ghanbari, S. A Green Approach to Synthesis of ZnO Nanoparticles Using Jujube Fruit Extract and Their Application in Photocatalytic Degradation of Organic Dyes. Spectrochim. Acta - Part A Mol. Biomol. Spectrosc. 2020, 229, 117961, https://doi.org/10.1016/j.saa.2019.117961.

4. Barathi, S.; Karthik, C.; S, N.; Padikasan, I. A. Biodegradation of Textile Dye Reactive Blue 160 by Bacillus 
Firmus (Bacillaceae: Bacillales) and Non-Target Toxicity Screening of Their Degraded Products. Toxicol. Reports 2020, 7, 16-22, https://doi.org/10.1016/j.toxrep.2019.11.017.

5. Samuchiwal, S.; Gola, D.; Malik, A. Decolourization of Textile Effluent Using Native Microbial Consortium Enriched from Textile Industry Effluent. J. Hazard. Mater. 2021, 402, 123835 , https://doi.org/10.1016/j.jhazmat.2020.123835.

6. Gola, D.; Tyagi, P. K.; Chauhan, N.; Malik, A.; Srivastava, S. K. Beauveria Bassiana Assisted Remediation of Chromium and Indanthane Blue. J. Environ. Chem. Eng. 2021, 9, 105552, https://doi.org/10.1016/j.jece.2021.105552.

7. Jain, A.; Ahmad, F.; Gola, D.; Malik, A.; Chauhan, N.; Dey, P.; Tyagi, P. K. Multi Dye Degradation and Antibacterial Potential of Papaya Leaf Derived Silver Nanoparticles. Environ. Nanotechnology, Monit. Manag. 2020, 100337, https://doi.org/10.1016/j.enmm.2020.100337.

8. Yang, Y.; Ali, N.; Khan, A.; Khan, S.; Khan, S.; Khan, H.; Xiaoqi, S.; Ahmad, W.; Uddin, S.; Ali, N.; Bilal, M. Chitosan-Capped Ternary Metal Selenide Nanocatalysts for Efficient Degradation of Congo Red Dye in Sunlight Irradiation. Int. J. Biol. Macromol. 2021, 167, 169-181, https://doi.org/10.1016/j.ijbiomac.2020.11.167.

9. Gola, D.; Malik, A.; Shaikh, Z. A.; Sreekrishnan, T. R. Impact of Heavy Metal Containing Wastewater on Agricultural Soil and Produce: Relevance of Biological Treatment. Environmental Processes 2016, 3, 10631080, https://doi.org/10.1007/s40710-016-0176-9.

10. Oguntade, A. O.; Adetunji, M. T.; Arowolo, T. A.; Salako, F. K.; Azeez, J. O. Use of Dye Industry Effluent for Irrigation in Amaranthus Cruentus L. Production: Effect on Growth, Root Morphology, Heavy Metal Accumulation, and the Safety Concerns. Arch. Agron. Soil Sci. 2015, 61, 865-876, https://doi.org/10.1080/03650340.2014.958820.

11. Mathur, M.; Gola, D.; Panja, R.; Malik, A.; Ahammad, S. Z. Performance Evaluation of Two Aspergillus Spp. for the Decolourization of Reactive Dyes by Bioaccumulation and Biosorption. Environ. Sci. Pollut. Res. 2018, 25, https://doi.org/10.1007/s11356-017-0417-0.

12. Garg, D.; Sarkar, A.; Chand, P.; Bansal, P.; Gola, D.; Sharma, S.; Khantwal, S.; Surabhi; Mehrotra, R.; Chauhan, N.; Bharti, R.K. Synthesis of Silver Nanoparticles Utilizing Various Biological Systems: Mechanisms and Applications_a Review. Prog. Biomater. 2020, 9, 1-15, https://doi.org/10.1007/s40204020-00135-2.

13. Maheshwaran, G.; Malai Selvi, M.; Selva Muneeswari, R.; Nivedhitha Bharathi, A.; Krishna Kumar, M.; Sudhahar, S. Green Synthesis of Lanthanum Oxide Nanoparticles Using Moringa Oleifera Leaves Extract and Its Biological Activities. Adv. Powder Technol. 2021, https://doi.org/10.1016/j.apt.2021.04.004.

14. Naranthatta, S.; Janardhanan, P.; Pilankatta, R.; Nair, S. S. Green Synthesis of Engineered CdS Nanoparticles with Reduced Cytotoxicity for Enhanced Bioimaging Application. ACS Omega 2021, 6, 8646-8655, https://doi.org/10.1021/acsomega.1c00519.

15. Parrey, S. H.; Maseet, M.; Ahmad, R.; Khan, A. B. Deciphering the Kinetic Study of Sodium Dodecyl Sulfate on Ag Nanoparticle Synthesis Using Cassia Siamea Flower Extract as a Reducing Agent. ACS Omega 2021, 6, 12155-12167, https://doi.org/10.1021/acsomega.1c00847.

16. Kumar, I.; Yaseen, B.; Gangwar, C.; Mishra, S. K.; Mohan Naik, R. Environmental Benign Synthesis and Characterization of Nickel Oxide Nanoparticles Using Chicken Egg White as Template and Evaluations of Their Antibacterial/Antifungal Activities. Mater. Today Proc. 2021, https://doi.org/10.1016/j.matpr.2021.03.735.

17. Acharya, D.; Satapathy, S.; Thathapudi, J. J.; Somu, P.; Mishra, G. Biogenic Synthesis of Silver Nanoparticles Using Marine Algae Cladophora Glomerata and Evaluation of Apoptotic Effects in Human Colon Cancer Cells. Mater. Technol. 2020, https://doi.org/10.1080/10667857.2020.1863597.

18. Ulagesan, S.; Nam, T. J.; Choi, Y. H. Biogenic Preparation and Characterization of Pyropia Yezoensis Silver Nanoparticles (P.y AgNPs) and Their Antibacterial Activity against Pseudomonas Aeruginosa. Bioprocess Biosyst. Eng., 2021, 44, 443-452, https://doi.org/10.1007/s00449-020-02454-X.

19. Korcan, S. E.; Kahraman, T.; Acikbas, Y.; Liman, R.; Ciğerci, İ. H.; Konuk, M.; Ocak, İ. Cyto-Genotoxicity, Antibacterial, and Antibiofilm Properties of Green Synthesized Silver Nanoparticles Using Penicillium Toxicarium. Microsc. Res. Tech. 2021, https://doi.org/10.1002/jemt.23802.

20. Owoseni-Fagbenro, K. A.; Saifullah, S.; Imran, M.; Perveen, S.; Rao, K.; Fasina, T. M.; Olasupo, I. A.; Adams, L. A.; Ali, I.; Shah, M. R. Egg Proteins Stabilized Green Silver Nanoparticles as Delivery System for Hesperidin Enhanced Bactericidal Potential against Resistant S. Aureus. J. Drug Deliv. Sci. Technol., 2019, 50, 347-354, https://doi.org/10.1016/j.jddst.2019.02.002. 
21. Sabouri, Z.; Akbari, A.; Hosseini, H. A.; Khatami, M.; Darroudi, M. Egg White-Mediated Green Synthesis of NiO Nanoparticles and Study of Their Cytotoxicity and Photocatalytic Activity. Polyhedron, 2020, 178, 114351, https://doi.org/10.1016/j.poly.2020.114351.

22. khoobi, M.; Moghimi, M.; Motlagh, G. H.; Sorouri, F.; Haririan, E. Cross-Linked Poly(Acrylic Acid) Hydrogel Loaded with Zinc Oxide Nanoparticles and Egg White Proteins for Antimicrobial Application. $J$. Inorg. Organomet. Polym. Mater., 2020, 30, 5234-5243, https://doi.org/10.1007/s10904-020-01619-1.

23. Saikia, J.; Gogoi, A.; Baruah, S. Nanotechnology for Water Remediation. In Environmental Nanotechnology, Springer, 2019, 195-211. https://doi.org/10.1007/978-3-319-98708-8_7.

24. Aghebati-Maleki, A.; Dolati, S.; Ahmadi, M.; Baghbanzhadeh, A.; Asadi, M.; Fotouhi, A.; Yousefi, M.; Aghebati-Maleki, L. Nanoparticles and Cancer Therapy: Perspectives for Application of Nanoparticles in the Treatment of Cancers. J. Cell. Physiol., 2020, 235, 1962-1972, https://doi.org/10.1002/jcp.29126.

25. Vasile, O. R.; Andronescu, E.; Truşcă, R.; Vasile, E.; Holban, A. M.; Chifiriuc, M. C.; Iordache, F.; Maniu, H.; Bleotu, C.; Neaç̧u, I. A.; et al. Structure-grain size-synthesis route of silver nanoparticles: A correlation with the cytotoxic effect Rom J Morphol Embryol., 2019, 60, 617-628.

26. Neacsu, I. A.; Leau, S. A.; Marin, S.; Holban, A. M.; Vasile, B. S.; Nicoara, A. I.; Ene, V. L.; Bleotu, C.; Albu Kaya, M. G.; Ficai, A. Collagen-Carboxymethylcellulose Biocomposite Wound-Dressings with Antimicrobial Activity. Materials (Basel)., 2021, 14, 1-19. https://doi.org/10.3390/ma14051153.

27. Pandey, S.; Do, J. Y.; Kim, J.; Kang, M. Fast and Highly Efficient Catalytic Degradation of Dyes Using אCarrageenan Stabilized Silver Nanoparticles Nanocatalyst. Carbohydr. Polym. 2020, 230, 115597, https://doi.org/10.1016/j.carbpol.2019.115597.

28. Akther, T.; Mathipi, V.; Kumar, N.S.; Davoodbasha, M.; Srinivasan, H. Fungal-Mediated Synthesis of Pharmaceutically Active Silver Nanoparticles and Anticancer Property against A549 Cells through Apoptosis. Environ. Sci. Pollut. Res. 2019, 26, 13649-13657, https://doi.org/10.1007/s11356-019-04718-w.

29. Gürbüz, M.U.; Elmac1, G.; Ertürk, A.S. In Situ Deposition of Silver Nanoparticles on Polydopamine-coated Manganese Ferrite Nanoparticles: Synthesis, Characterization, and Application to the Degradation of Organic Dye Pollutants as an Efficient Magnetically Recyclable Nanocatalyst. Appl. Organomet. Chem. 2021, e6284, https://doi.org/10.1002/aoc.6284.

30. Sengupta, A.; Sarkar, A. Synthesis and Characterization of Nanoparticles from Neem Leaves and Banana Peels: A Green Prospect for Dye Degradation in Wastewater. Ecotoxicology 2021, 1-12, https://doi.org/10.1007/s10646-021-02414-5.

31. Rajkumar, R.; Ezhumalai, G.; Gnanadesigan, M. A Green Approach for the Synthesis of Silver Nanoparticles by Chlorella Vulgaris and Its Application in Photocatalytic Dye Degradation Activity. Environ. Technol. Innov. 2021, 21, 101282, https://doi.org/10.1016/j.eti.2020.101282.

32. Thiyagarajan, K.; Bharti, V.K.; Tyagi, S.; Tyagi, P.K.; Ahuja, A.; Kumar, K.; Raj, T.; Kumar, B. Synthesis of Non-Toxic, Biocompatible, and Colloidal Stable Silver Nanoparticle Using Egg-White Protein as Capping and Reducing Agents for Sustainable Antibacterial Application. RSC Adv. 2018, 8, 23213-23229, https://doi.org/10.1039/C8RA03649G.

33. Chauhan, N.; Tyagi, A. K.; Kumar, P.; Malik, A. Antibacterial Potential of Jatropha Curcas Synthesized Silver Nanoparticles against Food Borne Pathogens. Front. Microbiol. 2016, https://doi.org/10.3389/fmicb.2016.01748.

34. Nguyen, V. T. Sunlight-Driven Synthesis of Silver Nanoparticles Using Pomelo Peel Extract and Antibacterial Testing. J. Chem. 2020, 2020, https://doi.org/10.1155/2020/6407081.

35. Khorrami, S.; Zarrabi, A.; Khaleghi, M.; Danaei, M.; Mozafari, M. R. Selective Cytotoxicity of Green Synthesized Silver Nanoparticles against the MCF-7 Tumor Cell Line and Their Enhanced Antioxidant and Antimicrobial Properties. Int. J. Nanomedicine 2018, 13, 8013-8024, https://doi.org/10.2147/IJN.S189295.

36. Mitra, C.; Gummadidala, P. M.; Merrifield, R.; Omebeyinje, M. H.; Jesmin, R.; Lead, J. R.; Chanda, A. Size and Coating of Engineered Silver Nanoparticles Determine Their Ability to Growth-Independently Inhibit Aflatoxin Biosynthesis in Aspergillus Parasiticus. Appl. Microbiol. Biotechnol. 2019, 103, 4623-4632, https://doi.org/10.1007/s00253-019-09693-3.

37. Elamawi, R. M.; Al-Harbi, R. E.; Hendi, A. A. Biosynthesis and Characterization of Silver Nanoparticles Using Trichoderma Longibrachiatum and Their Effect on Phytopathogenic Fungi. Egypt. J. Biol. Pest Control 2018, 28, 1-11, https://doi.org/10.1186/s41938-018-0028-1.

38. Jain, A.; Malik, A.; Kumar Malik, H. Mathematical Modelling of Seed-Mediated Size-Specific Growth of Spherical Silver Nanoparticles Using Azadirachta Indica Leaf Extract. J. Taibah Univ. Sci. 2020, 14, 873880, https://doi.org/10.1080/16583655.2020.1782642. 
39. Woźniak, A.; Malankowska, A.; Nowaczyk, G.; Grześkowiak, B. F.; Tuśnio, K.; Słomski, R.; ZaleskaMedynska, A.; Jurga, S. Size and Shape-Dependent Cytotoxicity Profile of Gold Nanoparticles for Biomedical Applications. J. Mater. Sci. Mater. Med. 2017, 28, 1-11, https://doi.org/10.1007/s10856-0175902-y.

40. Tyagi, S.; Tyagi, P. K.; Gola, D.; Chauhan, N.; Bharti, R. K. Extracellular Synthesis of Silver Nanoparticles Using Entomopathogenic Fungus: Characterization and Antibacterial Potential. SN Appl. Sci., 2019, 1, https://doi.org/10.1007/s42452-019-1593-y.

41. Muthukrishnan S, B. S.; Muthukumar M, S. M.; Rao MV, S. K. T. Catalytic Degradation of Organic Dyes Using Synthesized Silver Nanoparticles: A Green Approach. J. Bioremediation Biodegrad. 2015, 06, 1-9, https://doi.org/10.4172/2155-6199.1000312.

42. Albeladi, S. S. R.; Malik, M. A.; Al-Thabaiti, S. A. Facile Biofabrication of Silver Nanoparticles Using Salvia Officinalis Leaf Extract and Its Catalytic Activity towards Congo Red Dye Degradation. J. Mater. Res. Technol. 2020, 9, 10031-10044, https://doi.org/10.1016/j.jmrt.2020.06.074.

43. Muraro, P. C. L.; Mortari, S. R.; Vizzotto, B. S.; Chuy, G.; dos Santos, C.; Brum, L. F. W.; da Silva, W. L. Iron Oxide Nanocatalyst with Titanium and Silver Nanoparticles: Synthesis, Characterization and Photocatalytic Activity on the Degradation of Rhodamine B Dye. Sci. Rep. 2020, 10, 1-9, https://doi.org/10.1038/s41598-020-59987-0.

44. Chandhru, M.; Rani, S. K.; Vasimalai, N. Reductive Degradation of Toxic Six Dyes in Industrial Wastewater Using Diaminobenzoic Acid Capped Silver Nanoparticles. J. Environ. Chem. Eng. 2020, 8, 104225, https://doi.org/10.1016/j.jece.2020.104225.

45. Chatterjee, A.; Perevedentseva, E.; Jani, M.; Cheng, C.-Y.; Ye, Y.-S.; Chung, P.-H.; Cheng, C.-L. Antibacterial Effect of Ultrafine Nanodiamond against Gram-Negative Bacteria Escherichia Coli . J. Biomed. Opt. 2014, 20, 051014. https://doi.org/10.1117/1.jbo.20.5.051014.

46. Lee, W.; Kim, K. J.; Lee, D. G. A Novel Mechanism for the Antibacterial Effect of Silver Nanoparticles on Escherichia Coli. BioMetals 2014, 27, 1191-1201, https://doi.org/10.1007/s10534-014-9782-z. 